\title{
Wie wirken sich kulturelle Einflussfaktoren auf die berufliche Praxis im Auslandseinsatz aus?
}

1. Der Produktmanager eines großen deutschen Pharma-Unternehmens berichtet:

Ich habe zunächst drei Jahre in Ostasien gearbeitet und wurde dann in die USA versetzt. In Asien überfällt einen die Fremdheit gleich am ersten Tag, man spürt sie wie einen Hammerschlag. Es dauert Monate, bis man beginnt, hinter der Fremdheit hier und da auch Vertrautes zu entdecken.

In den USA habe ich es umgekehrt erlebt. Manche Äußerlichkeit mutet zwar zunächst auch fremd an, beispielsweise die Architektur der Städte, aber doch nicht so fremd wie in Asien. Ich habe das, was ich sah, auch ständig in Bezug zu Deutschland gesetzt. Ich habe mich mit Hoffnung, öfter aber auch mit Sorge gefragt: Wann wird es bei uns auch so sein wie hier? Schon in dieser Frage kommt ein gewisses $\mathrm{Maß}$ an Nähe zwischen Deutschland und den USA zum Ausdruck!

Mit den Menschen in den USA kam ich zunächst sehr gut zurecht: 'Leute wie du und ich', dachte ich. Aber je länger ich da war, desto fremder wurden sie mir - und dies in vielen Bereichen. Aus der heutigen Distanz betrachtet würde ich immer noch sagen, dass die Unterschiede insgesamt viel geringer sind als die zu meinen ostasiatischen Partner, aber es gab in den USA Momente, da war ich mir dessen gar nicht mehr so sicher, und zwar deshalb, weil wenig so lief wie ich es erwartet hatte.

Aber ein wichtiger Unterschied lag auch in meiner Herangehensweise an die beiden Kulturen: In Asien habe ich Fremdheit erwartet und dann manche Gemeinsamkeit gefunden. In Amerika habe ich Gemeinsamkeiten erwartet und bin auf viel Fremdes gestoßen (Thomas 2011, S. 17). 